\title{
BREAKFAST WITH VITAL
}

Rhiannon Pounds, a dental nurse and treatment coordinator in Telford (also on Vital's Reader Panel), tweeted this fantastic picture not long after the winter issue of Vital was published with the caption 'Sunday morning Vital!' Thank you to Rhiannon for letting us publish her photograph here.

Where do you read Vital? Tweet your picture to @Editorkate2, post it on www.facebook.com/vitalmagazine or email it to vitaleditorial@nature.com.

\section{ALL TEAMS NEED A VISION OR GOAL}

I read the article Lead the way to a tranquil workplace (Vital winter 2012;

42-44) with great enthusiasm and agreement.

Having

experienced the

daunting task of undertaking leadership of a young team five years ago I can fully support and endorse Seema's sentiment and advice.

Successful teams are created through ownership, communication, personal development and investment. I myself changed my leadership style three times in the last five years and this change coincided with Tuckman's four stages of team formation, adapting personal management styles to suit formation stages and creating team stability.

It is my belief all teams need a 'vision' or 'goal' and the leader or manager needs to be fully committed to that goal leading the team through their own example behaviour.

Now that my initial team are well established they 'manage themselves' through communication and delegation using a team management model as described in Glenys Bridges' book Dental practice management (see review page 11), working to their strengths whilst developing their weaknesses together.

This 'culture' has enabled me to widen my career path improving the chances of meeting my career aspirations and managing my time more effectively to be able to take on the responsibility of managing an additional practice.

I look forward to reading the following articles to come on refining team roles and can recommend Seema's sound advice to all practice managers.

\section{Claire Deegan RDN Cert DPM \\ Worthing}

\section{Vital reader panel}

New members of Vital's reader panel. Check out the feedback from our panel members in selected articles in this issue.

\section{Rhiannon Pounds}

Age: 30

Town: Wellington, Shropshire

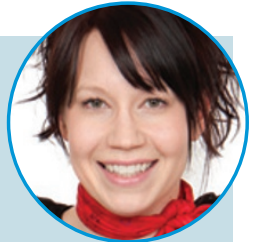

Place of work: The Smile

Works Limited

Job title: Dental Nurse and Treatment

Coordinator

In dentistry: 10 years

Loves: my two cats Floss and Tepe

Hates: Salad cream

\section{Sylvie Sturrock}

Age: can't remember

Town: Ealing, London

Place of work: The Neem

Tree Dental Group

Job title: Dental Business Manager

In dentistry: 30 years this May

(crikey Batman!)

Loves: turning dental practices into dental businesses

Hates: sequin Ugg boots

\section{Rachael England}

Age: 31

Town: Bracknell

Place of work: Warwick House Dental Surgery

Job title: Dental Hygienist

In dentistry: 16 years

Loves: my dog, Stella

Hates: tequila

If you would like to be on the reader panel, just drop the Editor, Kate Maynard, an email on vitaleditorial@nature.com or write to Vital reader panel, BDJ Editorial, 4-6 Crinan Street, London, N1 9XW.

$\lambda$ Snail mail: Vital Editorial, NPG, 4-6

Next issue's star letter writer will win Beverly Hills Formula goodies worth $£ 100$.

Letters may be edited for space. Opinions expressed do not necessarily reflect those of the editorial team or publishers. 